\title{
Yeast mitochondrial Gln-tRNA Gln is generated by a GatFAB-mediated transamidation pathway involving Arc1p-controlled subcellular sorting of cytosolic GluRS
}

\author{
Mathieu Frechin, ${ }^{1}$ Bruno Senger, ${ }^{1}$ Mélanie Brayé, ${ }^{1}$ Daniel Kern, ${ }^{1}$ Robert Pierre Martin, ${ }^{2,4}$ \\ and Hubert Dominique Becker ${ }^{1,3}$ \\ ${ }^{1}$ UPR 9002, "Architecture et Réactivité de l'ARN," Université de Strasbourg, CNRS, Institut de Biologie Moléculaire et \\ Cellulaire, F-67084 Strasbourg Cédex, France, ${ }^{2}$ UMR 7156, "Génétique Moléculaire, Génomique, Microbiologie," Department of \\ Molecular and Cellular Genetics, CNRS, Université de Strasbourg, 67084 Strasbourg, France
}

\begin{abstract}
It is impossible to predict which pathway, direct glutaminylation of tRNA ${ }^{\text {Gln }}$ or tRNA-dependent transamidation of glutamyl-tRNA ${ }^{\text {Gln }}$, generates mitochondrial glutaminyl-tRNA ${ }^{\text {Gln }}$ for protein synthesis in a given species. The report that yeast mitochondria import both cytosolic glutaminyl-tRNA synthetase and tRNA ${ }^{\text {Gln }}$ has challenged the widespread use of the transamidation pathway in organelles. Here we demonstrate that yeast mitochondrial glutaminyl-tRNA ${ }^{\mathrm{Gln}}$ is in fact generated by a transamidation pathway involving a novel type of trimeric tRNAdependent amidotransferase (AdT). More surprising is the fact that cytosolic glutamyl-tRNA synthetase (cERS) is imported into mitochondria, where it constitutes the mitochondrial nondiscriminating ERS that generates the mitochondrial mischarged glutamyl-tRNA ${ }^{\text {Gln }}$ substrate for the AdT. We show that dual localization of ${ }_{c} E R S$ is controlled by binding to Arc1p, a tRNA nuclear export cofactor that behaves as a cytosolic anchoring platform for cERS. Expression of Arc1p is down-regulated when yeast cells are switched from fermentation to respiratory metabolism, thus allowing increased import of ${ }_{c} E R S$ to satisfy a higher demand of mitochondrial glutaminyltRNA $^{\text {Gln }}$ for mitochondrial protein synthesis. This novel strategy that enables a single protein to be localized in both the cytosol and mitochondria provides a new paradigm for regulation of the dynamic subcellular distribution of proteins between membrane-separated compartments.
\end{abstract}

[Keywords: Dual localization; tRNA-dependent amidotransferase; tRNA ${ }^{\mathrm{Gln}}$; mitochondria; metabolism; Saccharomyces cerevisiae]

Supplemental material is available at http://www.genesdev.org.

Received December 12, 2008; revised version accepted March 13, 2009.

In all living organisms, ribosome-mediated protein synthesis requires the supply of a set of at least 20 perfectly paired aminoacyl-transfer RNA (aa-tRNA) species, one for each of the canonical amino acids found in proteins. Although most of the aa-tRNA is made by aminoacyltRNA synthetases (aaRS), a family of 20 enzymes that catalyze direct acylation of each tRNA species with its cognate amino acid (Ibba and Söll 2000), it is now clear that the process of aa-tRNA synthesis is far from universally conserved. In different organisms, up to four aatRNA species are, or can be, generated by two-step

Corresponding authors.

${ }^{3}$ E-MAIL h.becker@ibmc.u-strasbg.fr; FAX 33-3-88-60-22-18.

${ }^{4}$ E-MAIL r.martin@ibmc.u-strasbg.fr; FAX 33-3-88-41-70-70.

Article is online at http://www.genesdev.org/cgi/doi/10.1101/gad.518109. indirect pathways invariably involving tRNA-dependent conversion of a precursor mischarged aa-tRNA (Sheppard et al. 2008). These pathways, which usually compensate for the absence of a given aaRS, are not oddities of the translation machinery, since they sometimes constitute the sole route for synthesis of a given aa-tRNA. Among all aa-tRNA species used for mRNA translation, one, glutaminyl-tRNA ${ }^{\text {Gln }}\left(\mathrm{Q}^{-} \mathrm{tRNA}{ }^{\mathrm{Q}}\right)$, is of particular interest, not only because it displays the unique feature of being generated by kingdom-specific pathways or enzymes (Tumbula et al. 2000), but also because its synthesis is still a matter of debate and remains to be elucidated for the majority of eukaryotic organelles. To date, all eukaryotes studied so far use glutaminyl-tRNA synthetase (QRS) for the formation of cytosolic glutaminyl-tRNA ${ }^{\text {Gln }}$

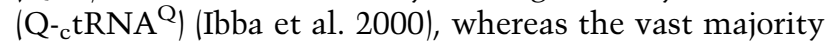


of prokaryotes use the two-step transamidation pathway in which two enzymes are working in tandem. First, a nondiscriminating glutamyl-tRNA synthetase (NDERS) generates a mischarged Glu-tRNA ${ }^{\text {Gln }}\left(\right.$ E-tRNA $^{\mathrm{Q}}$ ) (Lapointe et al. 1986), then, the glutamate-charged tRNA $^{\mathrm{Q}}$ is transamidated into glutamine by a tRNAdependent amidotransferase (AdT). The AdT enzymes catalyzing this process differ between bacteria and archaea. Bacteria solely use a heterotrimeric enzyme called the GatCAB AdT (Curnow et al. 1997; Becker and Kern 1998), while archaea utilize an archaeal-specific heterodimeric GatDE AdT (Tumbula et al. 2000).

The way Q-tRNA ${ }^{\mathrm{Q}}$ is generated in organelles is far from uniform among eukaryotes and is unknown for many organisms. The first report on organellar Q-tRNA ${ }^{\mathrm{Q}}$ synthesis came from experiments with barley chloroplast extracts, which unambiguously showed that Q-tRNA ${ }^{\mathrm{Q}}$ synthesis proceeds by transamidation of a mischarged glutamyl-tRNA $^{\text {Gln }}\left(\right.$ E-tRNA $^{\mathrm{Q}}$ ) (Schön et al. 1988). In addition, this work suggested that plant and mouse mitochondria use the same transamidation pathway to form mitochondrial glutaminyl-tRNA ${ }^{\text {Gln }}\left(\mathrm{Q}-{ }_{\mathrm{m}} \mathrm{tRNA}^{\mathrm{Q}}\right)$, based on the result that QRS activity could not be detected in any of the mitochondrial extracts that were assayed. The general idea that organellar and especially mitochondrial Q-tRNA ${ }^{\mathrm{Q}}$ synthesis uniformly proceeds via the transamidation pathway was later reinforced by accumulating sequence data coming from whole-genome sequencing projects. All eukaryotic genomes sequenced so far are deprived of the gene encoding a mitochondrial QRS $\left({ }_{m} \mathrm{QRS}\right)$. With the exception of a few protozoans, they concomitantly all display a gene for a GatB ortholog, named PET112, which is always predicted to encode a mitochondrial protein. Since the presence of a gatB gene in a given prokaryotic genome invariably signifies the presence of an AdT in the corresponding organism, the presence of mitochondrial GatB homologs (Pet112p) in eukaryotes should predict the existence of a mitochondrial AdT. Recent studies with Arabidopsis thaliana validated this assumption by showing that mitochondrial and chloroplastic Q-tRNA ${ }^{\mathrm{Q}}$ are actually made by a unique dual-targeted GatCAB AdT (Pujol et al. 2008) that transamidates both mitochondrial and chloroplastic E-tRNA ${ }^{\mathrm{Q}}$ formed by a unique mischarging ERS also addressed to both cellular compartments. This paradigm is, however, contradicted by two studies reporting the existence of a ${ }_{m}$ QRS in trypanosomatidae (Nabholz et al. 1997; Rinehart et al. 2004). Likewise, a recent study reported that in the yeast Saccharomyces cerevisiae, the ${ }_{\mathrm{c}} \mathrm{QRS}$ and two nuclear-encoded tRNAs ${ }^{\mathrm{Q}}$ are imported in the mitochondria and used to generate Q-tRNA ${ }^{\mathrm{Q}}$ that participates to mitochondrial protein synthesis (Rinehart et al. 2005). This result is somewhat surprising since it contradicts several earlier studies suggesting that yeast mitochondrial Q-tRNA ${ }^{\mathrm{Q}}$ was not generated by direct charging of mitochondrial tRNA ${ }^{\mathrm{Q}}$ by a $\mathrm{mQRS}$, but rather by a mitochondrial transamidation pathway. For example, it had been shown that the yeast gatB ortholog, PET112 (Mulero et al. 1994), is essential for respiratory metabolism and that the respiratory deficiency induced by its alteration can be rescued by expression of a mitochondrially targeted version of the Bacillus subtilis GatB subunit (Kim et al. 1997). This suggests that a mitochondrial AdT could well exist and be responsible for Q-tRNA ${ }^{\mathrm{Q}}$ formation in yeast mitochondria. However, Rinehart et al. (2005) demonstrated that the yeast mitochondrial glutamyltRNA synthetase $\left(\mathrm{m}_{\mathrm{m}} \mathrm{ERS}\right)$ is incapable of charging with glutamate any of the $\mathrm{tRNA}^{\mathrm{Q}}$ species present in yeast mitochondria. This constitutes a strong argument against the existence of a mitochondrial transamidation pathway in yeast. Indeed, if there is no ND-ERS in mitochondria, then the mischarged E-tRNA ${ }^{\mathrm{Q}}$, which is the obligatory substrate intermediate for the AdT, cannot be generated. Consequently, with no means of supplying the AdT with its substrate, the existence of a mitochondrial tRNAdependent transamidation pathway makes no sense. Yet, the $S$. cerevisiae genome encodes a mitochondrial GatB ortholog. The logical deduction one would make is that the yeast mitochondrial GatB protein, Pet112p, has deviated from its canonical function in tRNA-dependent transamidation and exhibits an essential alternative mitochondrial function. We therefore designed a series of experiments to identify the functional role of this protein.

Using a systems-based approach and despite expectations to the contrary, we characterized a novel type of trimeric AdT in yeast mitochondria. Biochemical, genetic, and subcellular localization experiments unambiguously prove that this AdT is mitochondrial and is responsible for $\mathrm{Q}-{ }_{\mathrm{m}} \mathrm{tRNA}{ }^{\mathrm{Q}}$ formation. We confirm that yeast ${ }_{\mathrm{m}}$ ERS is indeed a discriminating ERS and cannot produce $\mathrm{E}_{-\mathrm{m}} \mathrm{tRNA} \mathrm{Q}^{\mathrm{Q}}$. However, to our surprise, we found that the cytosolic ERS ( $\mathrm{c}$ ERS) can synthesize the mischarged E-tRNA ${ }^{\mathrm{Q}}$ substrate for the AdT. In agreement with this result, we found that a fraction of ${ }_{c}$ ERS localizes to mitochondria and is in fact the missing nondiscriminating ERS. By trying to understand how the ${ }_{\mathrm{c}}$ ERS can be dual localized, we found that the major portion of ${ }_{\mathrm{c}}$ ERS is sequestered in the cytoplasm by binding to Arclp, a protein that serves as a cytoplasmic anchoring platform for ${ }_{\mathrm{c}}$ ERS but also for cytosolic methionyl-tRNA synthetase $\left({ }_{\mathrm{c}} \mathrm{MRS}\right)$. Finally, we also found that the level of Arclp expression is decreased when the cells are switched from fermentation to respiratory metabolism, which results in increased ${ }_{c}$ ERS import to allow higher levels of Q- ${ }_{m} t_{R N A}{ }^{Q}$ formation for elevated mitochondrial protein synthesis. We propose that Arclp constitutes a relay in the molecular pathway that allows yeast cells to switch from fermentation to respiration. This constitutes a novel mechanism of regulation of dual localization of a protein that is used and essential in both the cytoplasm and mitochondria.

\section{Results}

The yeast mitochondrial GatB protein (Pet112p) participates in the assembly of an AdT-like trimeric particle

To identify Pet112p interactants, we engineered a yeast strain in which a tandem affinity purification (TAP) tag coding sequence was chromosomally fused, in-frame, to 
the $3^{\prime}$-end of PET112 (Puig et al. 2001). Figure 1A shows that fusion of this tag does not interfere with the mitochondrial function of the recombinant protein, since unlike the pet112 deletion strain (pet112s) (Supplemental Table 1), the PET112-TAP cells still grow on a respiratory medium. The Pet112-TAP fusion protein and associated components were recovered from cell extracts by TAP. Analysis of the final pull-down fraction by SDSPAGE showed several proteins associated with the Pet112 bait (Fig. 1B). Mass spectrometry analysis of the band recovered from the gel identified seven Pet112interacting proteins, among which two were annotated as mitochondrial and were present in stoichiometric amounts when compared with the Pet112-TAP fusion protein. These two interactants are Ymr293c and Ygr102c. Ymr293c is annotated as being an amidase that displays an amidohydrolase signature motif and is homologous to bacterial GatA proteins (Saccharomyces
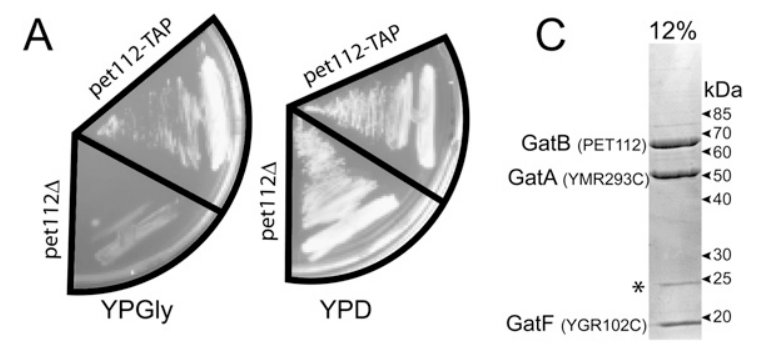

B

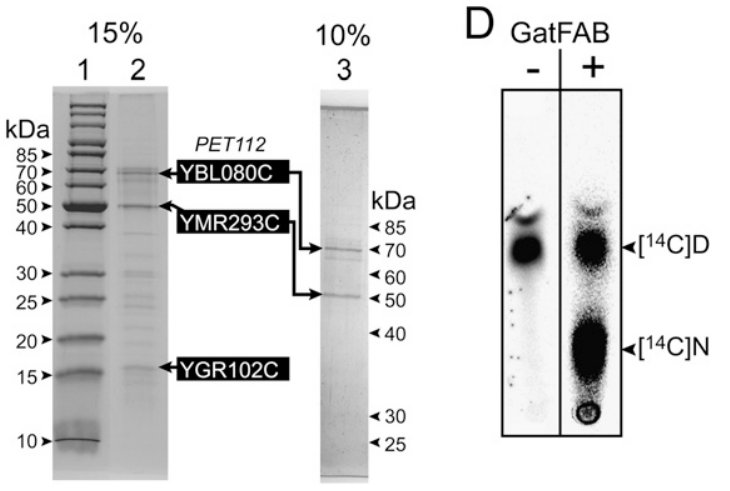

Figure 1. Identification of a GatCAB-like AdT in yeast. $(A)$

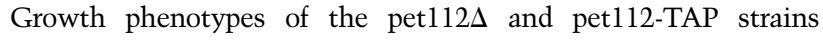
obtained in fermentation (YPD) and respiratory (YPGly) conditions after $48 \mathrm{~h}$ of incubation at $30^{\circ} \mathrm{C}$. Origin and engineering of the strains are described in the Materials and Methods and Supplemental Table 1. (B, lanes 2,3) G250 Colloidal Blue-stained SDS-PAGE separation of the Pet112-TAP interactants purified by TAP. (Lane 1) Molecular weight standards. The three putative mitochondrial proteins, identified by mass spectrometry, are highlighted. $(C)$ Coomassie Blue-stained SDS-PAGE of the overexpressed S. cerevisiae GatFAB AdT purified on an immobilized $\mathrm{Co}^{2+}$ column. The band labeled with an asterisk $\left({ }^{\star}\right)$ corresponds to contaminating E. coli prolyl-isomerase $(25 \mathrm{kDa}$; Mukherjee et al. 2003). (D) Autoradiogram of the TLC plate analyzing the conversion of $10 \mu \mathrm{M}$ tRNA ${ }^{\text {Asn }}$-bound $\left[{ }^{14} \mathrm{C}\right]$ aspartate $\left(\left[{ }^{14} \mathrm{C}\right] \mathrm{D}\right)$ into $\left[{ }^{14} \mathrm{C}\right]$ asparagine $\left(\left[{ }^{14} \mathrm{C}\right] \mathrm{N}\right)$ catalyzed by $0.1 \mu \mathrm{M}$ pure $S$. cerevisiae GatFAB AdT in the presence $(+)$ or absence $(-)$ of glutamine as an amide group donor. Aspartylation and transamidation reactions of the Thermus thermophilus tRNA ${ }^{\text {Asn }}$ were performed as described previously (Bailly et al. 2007).
Genome Database). In addition, YMR293C has recently been renamed HER2 (Hmg2p ER remodeling) because it has been reported to be involved in proliferation or remodeling of the endoplasmic reticulum that is caused by overexpression of Hmg2p (Federovitch et al. 2008). Ygr102c is a small protein of unknown function that has been detected in highly purified mitochondria in highthroughput studies (Reinders et al. 2006). When we crossed the available functional and structural data, we realized that we purified a mitochondrial heterotrimer composed of a GatB ortholog (Pet112), a GatA homolog (Ymr293c), and a small protein like GatC (Ygr102c), matching almost perfectly with the bacterial GatCAB AdT. To confirm the existence of this trimeric particle, we performed TAP on extracts of a strain expressing C-terminally TAP-tagged Ymr293c. Analysis of the purified fraction shows that Pet112p and Ygr102c coelute with the Ymr293c fusion protein (Supplemental Fig. 1). The three genes encoding Pet112p, Ymr293c, and Ygr102c were then synthetically reconstructed with codon optimization to allow efficient expression in Escherichia coli. For coexpression purposes, the three genes were subcloned into pET-20b in an operonal arrangement, and to facilitate identification and purification of the putative AdT, sequences encoding the V5 viral epitope and a $6 \mathrm{xHis}$ tag were fused to the $3^{\prime}$-end of PET112. E. coli strain BL21 was transformed with the overexpressing plasmid, and operon expression was induced. Figure 1C shows that Ymr293c and Ygr102c coelute with Pet112p from an immobilized $\mathrm{Co}^{2+}$ resin, showing that the three proteins can assemble into a trimer in the heterologous E. coli expression system. Having purified a particle that structurally resembles an AdT, we wanted to check whether this putative AdT can indeed catalyze tRNA-dependent transamidation. Since no mischarging ERS could be identified in yeast, and having shown that the plant mitochondrial GatCAB AdT (Pujol et al. 2008), like all GatCAB AdTs studied so far, can transamidate both E-tRNA ${ }^{\mathrm{Q}}$ and aspartyl-tRNA ${ }^{\text {Asn }}\left(\mathrm{D}\right.$-tRNA $\left.{ }^{\mathrm{N}}\right)$, we attempted transamidation of a heterologous bacterial D-tRNA ${ }^{\mathrm{N}}$ with the purified putative yeast AdT. Figure 1D shows that the yeast GatCAB-like AdT very efficiently transamidates Thermus thermophilus D-tRNA ${ }^{\mathrm{N}}$. This amidation is strictly tRNAdependent since pure yeast AdT does not convert free $\left[{ }^{14} \mathrm{C}\right]$ Asp into $\left[{ }^{14} \mathrm{C}\right]$ Asn (data not shown). While Pet112p and Ymr293c are highly similar to the bacterial GatB and GatA subunits, respectively, and can therefore be considered as real orthologs of GatB and GatA, Ygr102c has no similarity to any bacterial GatC subunit; we therefore named this subunit GatF. These lines of experiments show that using a systems-based approach we isolated a GatFAB trimeric AdT able to catalyze tRNA-dependent amidation of a mischarged D-tRNA ${ }^{\mathrm{N}}$.

Existence of a yeast mitochondrial tRNA-dependent transamidation pathway that generates glutaminy - $_{m} t R N A^{\text {Gln }}$

Although genetic experiments showed that Pet112p is a mitochondrial protein, evidence for a mitochondrial 
localization of Ymr293c and Ygr102c comes from whole high-throughput localization studies (http://www. yeastgenome.org; Huh et al. 2003). Moreover, no mitochondrial targeting sequence can be detected in Ymr293c using standard bioinformatics tools (http://ihg2.helmholtzmuenchen.de/ihg/mitoprot.html). We therefore examined the intracellular localization of the three subunits of our putative trimeric AdT by expressing in yeast versions of Pet112p, Ymr293c, and Ygr102c fused to GFP at their $\mathrm{C}$ termini. Adding the GFP tag does not interfere with the mitochondrial function of the recombinant proteins, since the yeast strains expressing the Gat-GFP fusion proteins instead of the normal Gat subunits do not display any growth defect when plated on respiratory medium (Supplemental Fig. 2). Figure 2A shows that all three proteins are localized within the mitochondria as demonstrated by the colocalization (merge) of GFP fluorescence with that of the red-MitoTracker. The observed mitochondrial GFP fluorescence is solely due to the fact that GFP is fused to mitochondrial-targeted proteins, since GFP alone has been reported to be exclusively

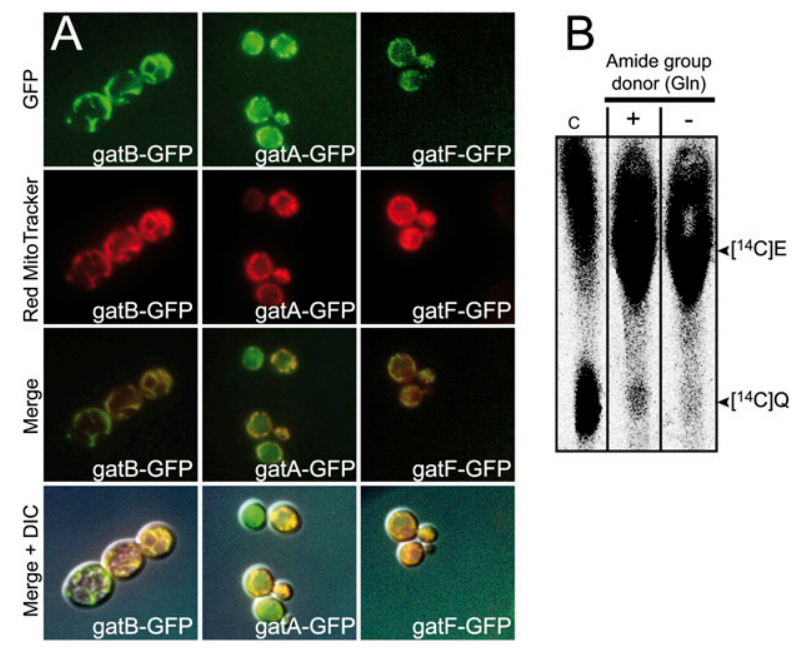

Figure 2. Mitochondrial localization and activity of the $S$. cerevisiae GatFAB AdT. (A) Visualization of the mitochondrial localization of the C-terminally GFP-tagged GatA, GatB, and GatF subunits by fluorescence microscopy. Yeast gatA-GFP, gatB-GFP, and gatF-GFP strains were logarithmically grown on synthetic medium as described in the Materials and Methods. Living cells were stained with Red MitoTracker and examined with a phase interference microscope as described in the Materials and Methods. GFP fluorescence can be overlapped with the Red MitoTracker staining of mitochondria. Note that a fraction of Ymr293c localizes also in the cytosol in agreement with a recent report on a possible additional function of this protein in this compartment (Federovitch et al. 2008). (B) Autoradiogram of the TLC plate showing the conversion of yeast mitochondrial tRNA-bound $\left[{ }^{14} \mathrm{C}\right] \mathrm{E}$ into $\left[{ }^{14} \mathrm{C}\right] \mathrm{Q}$ catalyzed by a yeast mitochondrial extract. Coupled aminoacylation and transamidation of $16 \mu \mathrm{g}$ of unfractionated mitochondrial tRNA, using $10 \mu \mathrm{g}$ of a tRNA-free mitochondrial protein extract, was performed in $50 \mu \mathrm{L}$ of transamidation buffer supplemented with $20 \mu \mathrm{M}$ of $\left[{ }^{14} \mathrm{C}\right] \mathrm{E}$ and with $(+)$ or without $(-) 1 \mathrm{mM}$ of glutamine (amide group donor). After $40 \mathrm{~min}$ of incubation, samples were treated as described in the Materials and Methods. cytosolic (Bordonné 2000; Navarro et al. 2004). Having confirmed by direct visualization that the three subunits localize to mitochondria, we checked whether mitochondrial extracts can catalyze transamidation of mitochondrial E-tRNA ${ }^{\mathrm{Q}}$ into Q-tRNA ${ }^{\mathrm{Q}}$. Total mitochondrial tRNA and total mitochondrial protein extract were assayed for the capacity of the protein extract to catalyze mischarging of ${ }_{\mathrm{m}} \mathrm{tRNA}{ }^{\mathrm{Q}}$ with $\left[{ }^{14} \mathrm{C}\right]$ glutamate $\left(\left[{ }^{14} \mathrm{C}\right] \mathrm{E}\right)$ and subsequent amidation of the $\left[{ }^{14} \mathrm{C}\right] \mathrm{E}$ into $\left[{ }^{14} \mathrm{C}\right]$ glutamine $\left(\left[{ }^{14} \mathrm{C}\right] \mathrm{Q}\right)$. Figure $2 \mathrm{~B}$ shows that the mitochondrial extract is able to generate a mischarged mitochondrial $\left[{ }^{14} \mathrm{C}\right] \mathrm{E}$ tRNA ${ }^{\mathrm{Q}}$ species and to convert the $\left[{ }^{14} \mathrm{C}\right] \mathrm{E}$ into $\left[{ }^{14} \mathrm{C}\right] \mathrm{Q}$ only in the presence of an amide group donor. The above results demonstrate that there exists a yeast mitochondrial tRNA-dependent transamidation pathway responsible for the formation of $\mathrm{Q}_{-\mathrm{m}} \mathrm{tRNA}^{\mathrm{Q}}$. This suggests that the mitochondrial GatFAB AdT we identified may well catalyze transamidation of E-tRNA ${ }^{\mathrm{Q}}$. However, while the transamidation that we observed using mitochondrial extracts undoubtedly shows that E-tRNA ${ }^{\mathrm{Q}}$ can be formed in yeast mitochondria, the nondiscriminating glutamyltRNA synthetase (ND-ERS) that generates this intermediate inside mitochondria remained to be identified.

\section{The cytosolic glutamyl-tRNA synthetase is nondiscriminating and charges the mitochondria- encoded $t R N A^{\text {Gln }}$ with glutamate}

It has been established that the $S$. cerevisiae genome encodes only two distinct ERSs, one being mitochondrial and the other cytosolic (Tzagoloff and Shtanko 1995; Gagnon et al. 1996). Furthermore, it has been shown that the ${ }_{m} E R S$ is of a discriminating nature and cannot generate the $\mathrm{E}_{\mathrm{m}} \mathrm{tRNA} \mathrm{R}^{\mathrm{Q}}$ obligatory substrate of the AdT (Rinehart et al. 2005). Our data fully support this result since the $\left[{ }^{14} \mathrm{C}\right] \mathrm{E}$-tRNA formed by charging of total mitochondrial tRNA with purified yeast ${ }_{\mathrm{m}} \mathrm{ERS}$ and $\left[{ }^{14} \mathrm{C}\right] \mathrm{E}$ does not yield any tRNA-dependent synthesis of $\left[{ }^{14} \mathrm{C}\right] \mathrm{Q}$ when incubated with pure yeast GatFAB AdT (Fig. 3A, inset i). Moreover, $\mathrm{tRNA}^{\mathrm{E}}$ is perfectly charged by ${ }_{\mathrm{m}} \mathrm{ERS}$, while ${ }_{\mathrm{m}} \mathrm{tRNA}^{\mathrm{Q}}$ is not (Fig. 3C). We then examined the possibility that the cytosolic glutamyl-tRNA synthetase ( $\left.{ }_{\mathrm{c}} \mathrm{ERS}\right)$ can carry out mischarging of ${ }_{\mathrm{m}} \mathrm{tRNA}^{\mathrm{Q}}$, despite the fact that this ERS has so far never been reported to be localized in mitochondria and does not display any identifiable mitochondrial targeting sequence (MTS). If ${ }_{c}$ ERS is capable of mischarging ${ }_{m}$ tRNA $^{\mathrm{Q}}$, then when the aminoacylation plateau of total mitochondrial tRNA with ${ }_{m}$ ERS is reached, addition of ${ }_{c} E R S$ should promote an increase in the aminoacylation plateau level because $a_{m}$ tRNA species different from ${ }_{m} t_{R N A}{ }^{E}$ would additionally be aminoacylated. Figure $3 \mathrm{~A}$ shows that upon addition of ${ }_{c}$ ERS there is an increase in the amount of ${ }_{m}$ tRNA that can be glutamylated. This increase is ${ }_{c}$ ERS-dependent since addition of the same amount of ${ }_{m}$ ERS resulted in an unchanged plateau level. The fact that the additional glutamylated ${ }_{m}$ tRNA formed by ${ }_{c}$ ERS can be transamidated by purified yeast GatFAB AdT confirms that ${ }_{\mathrm{c}}$ ERS mischarges ${ }_{\mathrm{m}}$ tRNA $^{\mathrm{Q}}$ (Fig. 3A, inset ii). However, it has been reported that three tRNA ${ }^{\mathrm{Q}}$ species can be 
A
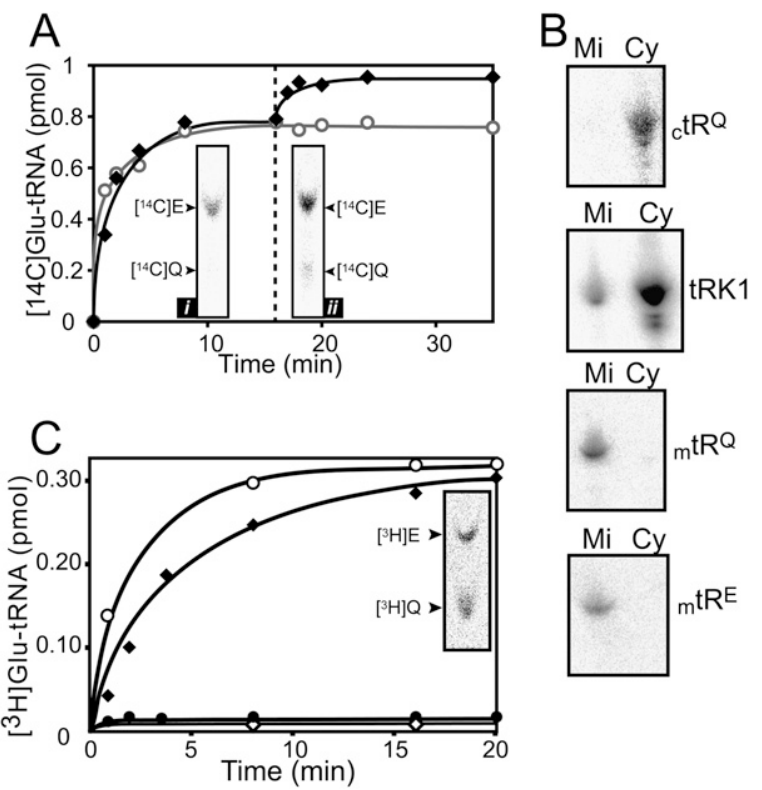

Figure 3. Identification of the missing nondiscriminating ERS and of the AdT tRNA ${ }^{\mathrm{Q}}$ substrate. (A) Aminoacylation curves of unfractionated ${ }_{m}$ tRNA with ${ }_{m}$ ERS and subsequent addition of ${ }_{m}$ ERS (-O-) or ${ }_{c}$ ERS (- -) when the aminoacylation plateau with ${ }_{\mathrm{m}}$ ERS was reached (16 min, dashed line). Autoradiogram of the TLC plate analyzing transamidation by purified yeast GatFAB AdT of $\left[{ }^{14} \mathrm{C}\right] \mathrm{E}_{-\mathrm{m}} \mathrm{tRNA}(40 \mu \mathrm{L})$ generated at plateau level by ${ }_{\mathrm{m}}$ ERS (inset $i$ ) or generated at plateau level by combined charging with ${ }_{\mathrm{m}}$ ERS and ${ }_{\mathrm{c}}$ ERS (inset ii). (B) Identification by Northern blotting of the tRNA ${ }^{\mathrm{Q}}$ and $\mathrm{tRNA}^{\mathrm{E}}$ species present in our unfractionated

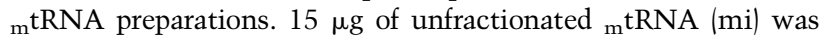
hybridized with probes specific for mitochondrial-encoded $\mathrm{tRNA}^{\mathrm{Q}}\left({ }_{\mathrm{m}} \mathrm{tR}^{\mathrm{Q}}\right)$, $\mathrm{tRNA}^{\mathrm{E}}\left({ }_{\mathrm{m}} \mathrm{tR}^{\mathrm{E}}\right)$, and nuclear-encoded $\mathrm{tRNA}^{\mathrm{Q}}\left({ }_{\mathrm{c}} \mathrm{tR}^{\mathrm{Q}}\right)$ and tRNA ${ }^{\mathrm{K}}$ (tRK1) shown previously to be imported into mitochondria. As a control, $15 \mu \mathrm{g}$ of unfractionated ${ }_{\mathrm{c}}$ tRNA (cy) was probed with the same probes. $(C)$ Charging curves of purified ${ }_{\mathrm{m}} \mathrm{tRNA}^{\mathrm{Q}}$ and ${ }_{\mathrm{m}} \mathrm{tRNA}^{\mathrm{E}}$ by ${ }_{\mathrm{c}} \mathrm{ERS}$ (respectively, - $\bullet$ - and $-\bullet-$ ) and ${ }_{\mathrm{m}}$ ERS (respectively, $-\diamond$ - and -O-). (Inset) Transamidation of the pure mischarged $\left[{ }^{14} \mathrm{C}\right] \mathrm{E}-\mathrm{m}_{\mathrm{m}} \mathrm{RNA}{ }^{\mathrm{Q}}$ by pure yeast GatFAB AdT.

found in yeast mitochondria: one mitochondrial-encoded species and two nuclear-encoded species $\left({ }_{c}\right.$ tRNAs $\left.{ }^{\mathrm{Q}}\right)$ that are mainly cytosolic but that are also imported to some extent into these organelles (Rinehart et al. 2005). To identify the tRNA $^{\mathrm{Q}}$ species charged by ${ }_{\mathrm{c}} \mathrm{ERS}$ and subsequently transamidated by the AdT, we probed, by Northern-blotting, our total mitochondrial tRNA preparation for the presence of the three $\mathrm{RNA}^{\mathrm{Q}}$ species using a probe specific for ${ }_{m} \mathrm{tRNA}^{\mathrm{Q}}$ and one that hybridizes to both ${ }_{c} t_{R N A s}{ }^{\mathrm{Q}}$ that are believed to be imported from the cytoplasm. Figure 3B shows that the total mitochondrial tRNA contains both ${ }_{m}$ tRNA $^{\mathrm{Q}}$ and ${ }_{m} \mathrm{tRNA}^{\mathrm{E}}$ and that our probes are highly specific since they do not cross-hybridize to any cytosolic tRNA species. While we could, as expected, detect the presence of both ${ }_{c} \mathrm{tRNAs}^{\mathrm{Q}}$ species in the total cytosolic tRNA sample, we could not detect any trace of these two tRNAs in our mitochondrial tRNA sample (Fig. 3B). We confirmed that absence of ${ }_{c}$ tRNAs $^{\mathrm{Q}}$ in our mitochondrial tRNA sample was not biased by the extraction procedure, since it contained tRK1 (Fig. 3B), a yeast cytosolic tRNA ${ }^{\text {Lys }}$ that has been shown to be imported at a level of $5 \%$ in yeast mitochondria (Martin et al. 1979; Entelis et al. 1998). Figure 3B shows that the amount of tRK1 present in our mitochondrial tRNA corresponds to the expected quantity.

These data show that ${ }_{\mathrm{c}}$ ERS has the potential to be the missing nondiscriminating ERS used for the mitochondrial transamidation pathway, since it is capable of charging the ${ }_{\mathrm{m}} \mathrm{tRNA}^{\mathrm{Q}}$ (Fig. 3C). In addition, the inset in Figure $3 \mathrm{C}$ shows that the $\mathrm{E}_{{ }_{\mathrm{m}}} \mathrm{tRNA} \mathrm{A}^{\mathrm{Q}}$ generated by ${ }_{\mathrm{c}} \mathrm{ERS}$ can subsequently be transamidated by the recombinant yeast GatFAB. Notably, while cERS is able to charge ${ }_{c} \mathrm{tRNA}^{\mathrm{E}}$, it is unable to charge the ${ }_{\mathrm{m}} \mathrm{tRNA}^{\mathrm{E}}$ (Fig. 3C).

\section{A fraction of the cytoplasmic glutamyl-tRNA synthetase is imported into mitochondria}

While the yeast ${ }_{c}$ ERS possesses all the biochemical features of the missing ND- ${ }_{m}$ ERS that catalyzes the first step of the transamidation pathway, it was not known whether this enzyme can be imported into mitochondria. When compared with prokaryotic ERSs, the yeast ${ }_{\mathrm{c}}$ ERS possesses 200 additional residues appended to the $\mathrm{N}$ terminus. While this additional domain does not display any recognizable MTS, we hypothesized that a nonconventional signaling sequence might be embedded in this part of the protein. We therefore constructed a series of ${ }_{c}$ ERS N-terminal deletion mutants with the expectation of cleaving off the signaling sequence without impairing the cytoplasmic catalytic activity of this enzyme (Fig. 4A). Such mutant ${ }_{\mathrm{c}}$ ERSs should still be able to promote growth on fermentable medium (glucose) but not on respiratory medium (glycerol). We used a yeast shuffling strain in which a plasmid-borne wild-type ${ }_{c}$ ERS gene complements the chromosomal deletion of this gene. This strain was transformed with the recombinant plasmids expressing our three deletion mutants and subsequently plated on 5-FOA to select for loss of the plasmid encoding wild-type ${ }_{\mathrm{c}}$ ERS. Figure $4 \mathrm{~B}$ shows that growth on glucose and glycerol media of the strains expressing either $\Delta \mathrm{N} 90{ }_{\mathrm{c}} \mathrm{ERS}$ (cers $\Delta 90$ ) or $\Delta \mathrm{N} 190{ }_{\mathrm{c}} \mathrm{ERS}$ (cers $\Delta 190)$ is comparable with that of the wild-type strain (cersfl). However, growth of the cers $\Delta 199$ strain that expresses the $\Delta$ N199- $E R S$ mutant is severely impaired in respiratory conditions but is almost unchanged on fermentable medium when compared with the wild-type strain (Fig. 4B). The petite phenotype observed for the cers $\Delta 199$ mutant strain demonstrates that ${ }_{\mathrm{c}}$ ERS has an essential mitochondrial function that is lost upon removal of its $\mathrm{N}$-terminal extension. Since the catalytic activity of the mutant $\Delta$ N199 ${ }_{\mathrm{c}}$ ERS seems unaltered in the cytoplasm, the deletion very likely hindered the import of the mutant ${ }_{c}$ ERS into mitochondria. To confirm that the ${ }_{\mathrm{c}}$ ERS is imported into mitochondria, we probed protein extracts from purified mitochondria for the presence of ${ }_{c}$ ERS using antibodies directed against yeast ${ }_{c}$ ERS. Figure 5A shows that ${ }_{c}$ ERS is present in mitochondria of a wild-type yeast strain. When compared with the amount found in a cytosolic fraction from the same strain, it appears that a significant amount of ${ }_{c} E R S$ is 


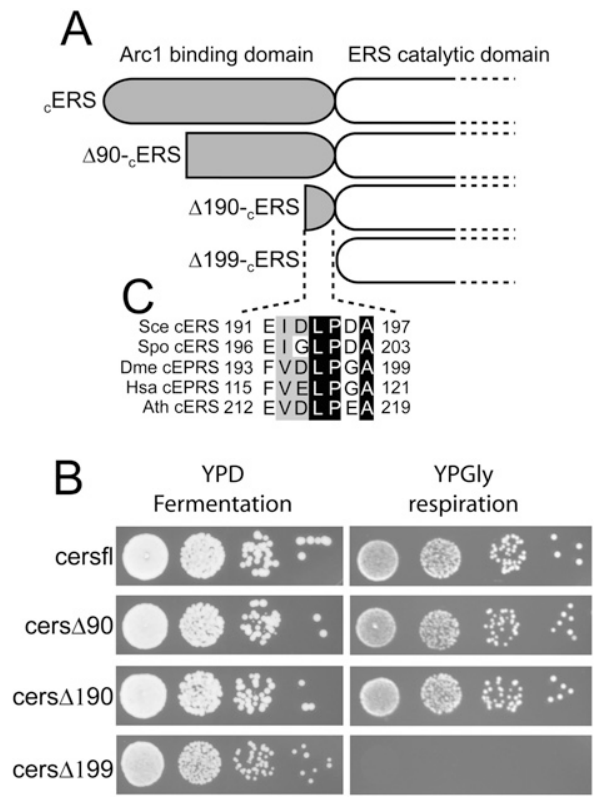

Figure 4. A noncanonical MTS located after the first 190 residues of ${ }_{C} E R S$ is responsible for its mitochondrial import. (A) Schematic representation of the different ${ }_{c}$ ERS variants. (B) Growth phenotypes on fermentative (YPD) or respiratory (YPGly) media of haploid $S$. cerevisiae cersfl, cers $\Delta 90$, cers $\Delta 190$, and cers $\Delta 199$ strains (see Supplemental Table 1). (C) Multiple alignment of $S$. cerevisiae ${ }_{\mathrm{c}}$ ERS with other eukaryotic ${ }_{c}$ ERSs and glutamyl-prolyl-tRNA synthetases (EPRS). (Sce) S. cerevisiae, (Spo) Schizosaccharomyces pombe, (Dme) Drosophila melanogaster, (Ath) A. thaliana, (Hsa) Homo sapiens. The region analyzed corresponds to the residues 190199 of the S. cerevisiae cERS. Black shading denotes 100\% amino acid identity, while gray signifies at least $80 \%$ homology (amino acid conservation in at least four out of the five proteins).

imported into the mitochondria. Our mitochondrial extracts were free of any cytosolic contaminants as shown by the absence of a cytosolic marker (PGK) in the mitochondrial proteins. To further confirm that the MTS of ${ }_{c}$ ERS is embedded within its first 199 residues, we subcloned into pRS315 the part of the ${ }_{c}$ ERS gene encoding the first 199 amino acids in-frame and upstream of the gene encoding GFP $\left(\mathrm{N}_{\mathrm{c}} \mathrm{ERS}\right.$-GFP). The chimeric gene was cloned under the control of its own promoter in order to not bias the amount of $\mathrm{N}_{\mathrm{c}}$ ERS-GFP that would be targeted to the mitochondria by overexpression of the fusion protein. The transformed yeast cells were grown in respiratory conditions, and the subcellular localization of the $\mathrm{N}_{\mathrm{c}}$ ERS-GFP was analyzed by confocal laser scanning microscopy. Figure 5B (top panels) shows that $\mathrm{N}_{\mathrm{c}} \mathrm{ERS}-$ GFP, as expected, is abundantly localized in the cytoplasm. However, a visible amount of $\mathrm{N}_{\mathrm{c}}$ ERS-GFP is undoubtedly localized in mitochondria, as shown by overlapping GFP and red MitoTracker signals (Fig. 5B, white arrows). Since we used a focal plane as thin as 900 $\mathrm{nm}$, the portion of the GFP fluorescence that colocalizes with the red MitoTracker emission cannot be due to interfering cytosolic GFP fluorescence that would overlap mitochondria. This demonstrates that the MTS of ${ }_{\mathrm{c}} \mathrm{ERS}$ is indeed localized within the $199 \mathrm{~N}$-terminal residues. Taking into account that the $\Delta$ N190- $E$ ERS variant did not induce respiratory deficiency whereas the $\Delta$ N199cERS variant did, the MTS is very likely localized between residues 191 and 199.

These lines of experimental evidence demonstrate that cERS, in addition to being nondiscriminating, is also mitochondrial. Therefore, upon import into the organelle, $c$ ERS is able to synthesize the mischarged $\mathrm{E}_{-\mathrm{m}} \mathrm{tRNA}^{\mathrm{Q}}$ that will subsequently be transamidated by the mitochondrial GatFAB AdT, generating the Q- $\mathrm{tRNA}^{\mathrm{Q}}$ necessary for mitochondrial protein synthesis.
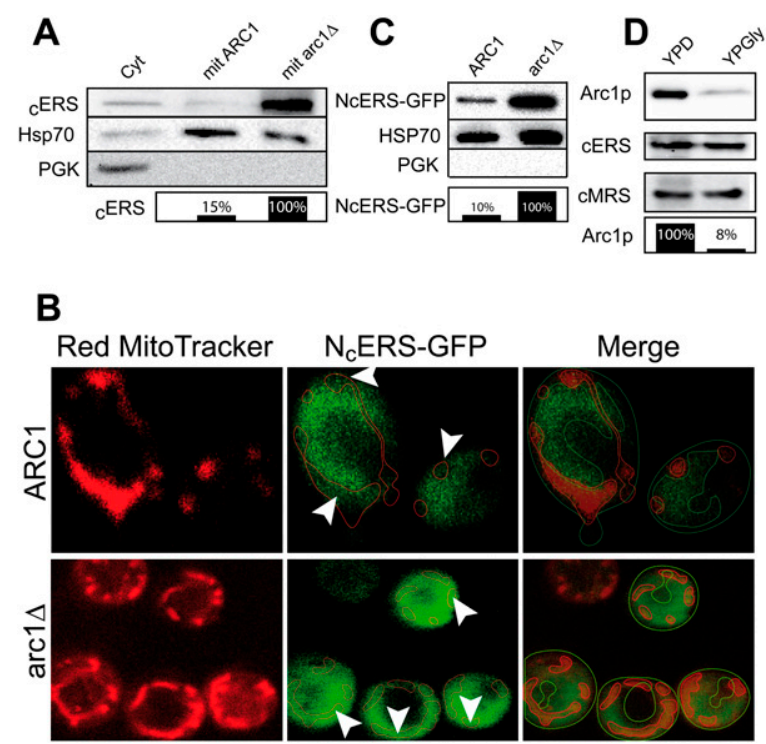

Figure 5. ${ }_{\mathrm{c}}$ ERS is maintained in the cytosol by binding to Arclp, a cytosolic retention platform, whose expression is down-regulated in response to a switch from fermentation to respiration. (A) Immunodetection, by Western blot, of ${ }_{c}$ ERS in purified cytosolic (cyt) and mitochondrial (mit) protein extracts of ARC1 (wild type, RS354) or arc1s strains. Amounts of total protein and cross-contamination of each mitochondrial extract were controlled using antibodies against Hsp70 (Hsp70) as a mitochondrial marker and against phosphoglycerokinase (PGK) as a cytosolic marker. $(B)$ Analysis of the subcellular localization of $\mathrm{N}_{\mathrm{c}}$ ERS-GFP in ARC1 (wild type, RS354) or arc1 $\Delta$ yeast strains transformed with pRS315/Nter ${ }_{\mathrm{c}}$ ERS-GFP. Living cells were stained with Red MitoTracker and examined with a confocal microscope as described in the Materials and Methods. Cellular areas where fluorescence of NcERS-GFP overlaps with the Red MitoTracker staining of mitochondria are indicated by white arrowheads. $(C)$ Western blot quantification of import of $\mathrm{N}_{\mathrm{c}}$ ERSGFP in mitochondria of ARC1 (wild type, RS354) or arc1s strains. Amounts of total protein and level of cytosolic contamination of each mitochondrial extract were controlled using anti-Hsp70 (Hsp70) and anti-PGK (PGK) antibodies, respectively. $(D)$ Western blot quantification of the variation in expression, by wild-type yeast strain (ARC1), of Arclp, cERS, and ${ }_{\mathrm{c}}$ MRS during fermentation (YPD) or respiration (YPGly). Histograms representing quantifications of the relative amounts of ${ }_{\mathrm{c}}$ ERS $(A)$, $\mathrm{N}_{\mathrm{c}}$ ERS-GFP $(C)$, and Arclp $(D)$ present in extracts were performed with ImageJ software. 
Arc1p acts as a cytosolic anchoring platform for regulated retention of cERS in the cytoplasm

An important issue raised by our findings is the understanding of the mechanism that regulates the dual localization of ${ }_{c} E R S$, since its activity is essential for both cytosolic and mitochondrial protein synthesis. It is already known from previous studies that both yeast ${ }_{c}$ ERS and cytosolic methionyl-tRNA synthetase (cMRS) are associated with Arclp, a cofactor of nuclear export (Simos et al. 1996). Interaction of ${ }_{c}$ MRS and ${ }_{c} E R S$ with Arclp, mediated by their $\mathrm{N}$ termini (Deinert et al. 2001), increases their tRNA aminoacylation efficiencies and prevents nuclear translocation of the two aaRS (Galani et al. 2001). While nuclear localization of ${ }_{c}$ MRS has been confidently shown, the nuclear localization of yeast ${ }_{c}$ ERS is somewhat less clear (Golinelli-Cohen and Mirande 2007). Since Arclp entraps yeast ${ }_{c}$ ERS in the cytosol, we surmised that this aaRS is preferentially a mitochondrial protein, and that Arclp captures and holds in the cytoplasm the portion of ${ }_{\mathrm{c}}$ ERS required for cytosolic translation. To verify this hypothesis, we checked by Western blotting whether removal of Arclp directly impacts the fraction of ${ }_{\mathrm{c}} \mathrm{ERS}$ addressed to the mitochondrion. Figure 5A shows that, indeed, in an Arclp deletion strain $(\operatorname{arc} 1 \Delta)$, the pool of ${ }_{c}$ ERS imported into mitochondria is drastically increased when compared with the amount found in mitochondria purified from the wild-type strain (ARC1). The absence of PGK and presence of HspP70 in comparable amounts in both the $\operatorname{arc} 1 \Delta$ and wildtype (ARC1) mitochondrial extracts shows that there is no contamination by a cytosolic portion of ${ }_{\mathrm{c}}$ ERS and that comparable amounts of total mitochondrial protein extracts were subjected to PAGE and transferred onto the membrane. A similar result was observed when comparing, by confocal laser scanning microscopy, the amount of the $\mathrm{N}_{\mathrm{c}}$ ERS-GFP fusion protein addressed to mitochondria in wild type (ARC1) and an $\operatorname{arc} 1 \Delta$ strain transformed with the plasmid expressing $\mathrm{N}_{\mathrm{c}}$ ERS-GFP. Figure $5 \mathrm{~B}$ shows that the portion of $\mathrm{N}_{\mathrm{c}} \mathrm{ERS}$-GFP addressed to the organelle, in the absence of Arclp, is increased in such a manner that the intensity of the mitochondrial fluorescence signal equals that of the cytosolic one. We observed a comparable increased import of $\mathrm{N}_{\mathrm{c}}$ ERS-GFP in the arc1s mutant as compared with the wild type by Western blotting using anti-GFP antibodies (Fig. 5C). These experiments confirm that Arclp retains in the cytoplasm a pool of ${ }_{c}$ ERS that otherwise would naturally be imported by mitochondria. Taking into account that the mitochondrial pool of ${ }_{\mathrm{c}} \mathrm{ERS}$ is increased by more than one order of magnitude upon depletion of Arclp, we conclude that, in an arc1 14 background, cERS is preferentially a mitochondrial protein.

Increased import of ${ }_{c} E R S$ into mitochondria is needed only when yeast cells are grown on a respiratory carbon source, suggesting that Arclp regulates the subcellular sorting of ${ }_{\mathrm{c}} \mathrm{ERS}$ in response to metabolic changes. Figure $5 \mathrm{D}$ indeed shows that the amount of Arclp is drastically decreased when yeast uses respiration as compared with fermentation, while the content of ${ }_{\mathrm{c}}$ MRS and ${ }_{\mathrm{c}}$ ERS does not vary. In addition, in cells grown on glucose, cERS, cMRS, and Arclp seem to be present in stoichiometric amounts, in agreement with previous studies reporting that Arclp always copurifies with equivalent amounts of ${ }_{c}$ ERS and ${ }_{c}$ MRS (Graindorge et al. 2005). During respiration, however, there is an excess of free ${ }_{c}$ ERS and ${ }_{c}$ MRS that can be addressed to their target subcellular compartments, the mitochondria and the nucleus, respectively. These results demonstrate that Arclp is a cytosolic retention platform for ${ }_{\mathrm{c}} \mathrm{ERS}$ and ${ }_{\mathrm{c}} \mathrm{MRS}$, whose amounts are regulated in response to the switch from fermentation to respiration to allow relocalization of these cytosolic aaRSs into organelles.

\section{Discussion}

The work described herein reopens the debate on how Q-tRNA ${ }^{\mathrm{Q}}$ synthesis is achieved in yeast mitochondria and more generally in other eukaryotic species. Recent studies have reported that import of both ${ }_{c} \mathrm{tRNA}^{\mathrm{Q}}$ and cQRS was needed for mitochondrial Q-tRNA ${ }^{\mathrm{Q}}$ synthesis in yeast (Rinehart et al. 2005) and that mammalian mitochondria also import ${ }_{c} \mathrm{tRNA}^{\mathrm{Q}}$ (Rubio et al. 2008). This led to a change of paradigm concerning organellar Q-tRNA ${ }^{\mathrm{Q}}$ synthesis that was, until these reports, assumed to uniformly proceed via tRNA-dependent transamidation (Schön et al. 1988). Our work unambiguously demonstrates that in yeast, mitochondria use the transamidation pathway to generate $\mathrm{Q}_{-\mathrm{m}} \mathrm{tRNA}^{\mathrm{Q}}$ (Fig. 6), and that this pathway is essential and sufficient for mitochondrial translation since deletion of any of the AdT subunit genes or suppression of the mitochondrial targeting capacity of the ND-ERS induces a respiratory deficiency. Beyond the discovery of a mitochondrial trimeric AdT in S. cerevisiae, we also found orthologs of the PET112 and YMR293C genes in all fungal genomes that are complete and accessible (http://cbi.labri.fr/Genolevures). However, recognizable orthologs of YGR102C (encoding GatF) could only be found in the Kluyveromyces lactis (gi:50307515) and Candida glabrata (gi:50288545) genomes. The human genome encodes, in addition to orthologs of the gat $A$ (YMR293C) and gatB (PET112) genes, an ortholog of the bacterial gatC gene (gatA: gi:19923522, gatB: gi:4758893, gatC: gi:50978623). Two of these gene products, GatB and $\mathrm{GatC}$, like in yeast, display the sequence of a canonical MTS. We are therefore confident that most, if not all, eukaryotes use the transamidation pathway to generate $\mathrm{Q}_{-\mathrm{m}} \mathrm{tRNA}{ }^{\mathrm{Q}}$. It has been recently confirmed that this is the case in A. thaliana mitochondria (Pujol et al. 2008).

In addition, our experiments indicate that the yeast mitochondrial-encoded tRNA ${ }^{\mathrm{Q}}$ is the only tRNA ${ }^{\mathrm{Q}}$ used by the mitochondrial translation apparatus, since our mitochondrial tRNA preparations were always deprived of any trace of nuclear-encoded tRNA ${ }^{\mathrm{Q}}$. Indeed, in conditions where the cytoplasmic lysine tRNA isoacceptor (tRK1) was well detected in our mitochondrial tRNA preparations, the ${ }_{\mathrm{c}} \mathrm{tRNA}{ }^{\mathrm{Q}}$ were undetectable. It has been proposed that the mitochondrial import of nuclearencoded ${ }_{c} \mathrm{RRNA}^{\mathrm{Q}}{ }_{\mathrm{CUG}}$ is required for the decoding of CAG glutamine codons in mitochondrial translation 
Figure 6. Subcellular localization, ligand binding, and activities of the proteins and RNA involved in S.cerevisiae Q-m $\mathrm{tRNA}^{\mathrm{Q}}$ formation. In $S$. cerevisiae, the mitochondrial $(\mathrm{m})$ tRNA $^{\mathrm{Q}}$ is glutamylated by a fraction of the cytosolic (c) ERS imported into mitochondria. The mitochondrial E-tRNA ${ }^{\mathrm{Q}}$ is then transamidated into Q-tRNA ${ }^{\mathrm{Q}}$ by a mitochondrial GatFAB AdT. Formation of the mitochondrial E-tRNA ${ }^{\mathrm{E}}$ is mediated solely by the mitochondrial ortholog $\left({ }_{\mathrm{m}}\right.$ ERS) of the ${ }_{\mathrm{c}}$ ERS. A portion of the ${ }_{\mathrm{c}} \mathrm{ERS}$ is maintained in the cytosol by binding to Arclp that additionally by capturing the cytosolic MRS hinders its nuclear addressing. Both enzymes are essential to the cytosolic translation since they catalyze formation of the cytosolic E-tRNA ${ }^{\mathrm{E}}$ and $\mathrm{M}$-tRNA ${ }^{\mathrm{M}}$, respectively.

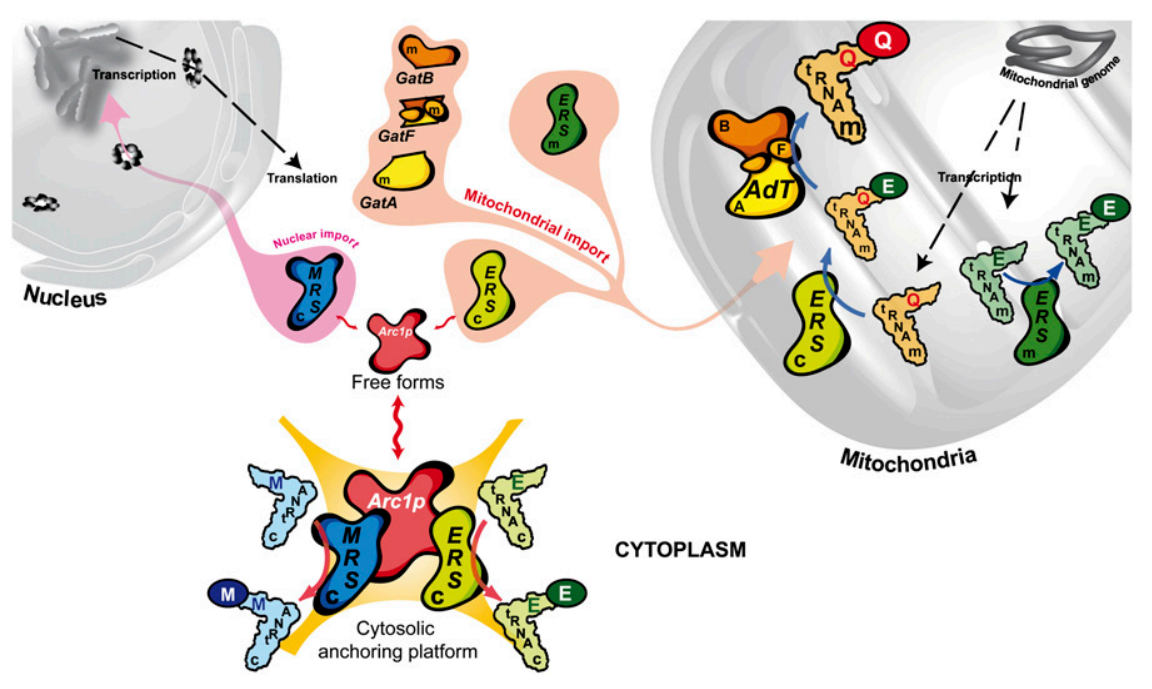

because the uridine modification, $\mathrm{cmnm}^{5} \mathrm{~s}^{2} \mathrm{U}$, in the wobble position of the anti-codon of $\mathrm{m}_{\mathrm{tRNA}} \mathrm{Q}^{\mathrm{C}}$ would restrict the reading to only CAA glutamine codons (Rinehart et al. 2005). However, all other reports published so far point out that $\mathrm{cmnm}^{5} \mathrm{~s}^{2} \mathrm{U}$ is able to pair with both A and G in the codon's third position (Yokoyama and Nishimura 1995; Umeda et al. 2005; Kurata et al. 2008), implying that $\mathrm{m}_{\mathrm{tRNA}}^{\mathrm{Q}}\left(\mathrm{cmnm}^{5} \mathrm{~s}^{2} \mathrm{U}\right)$ is able to decode both CAA and CAG glutamine codons. In this respect, we may notice that the yeast mitochondrialcoded ${ }_{m}$ tRNA $^{\text {Lys }}$, which bears the same $\mathrm{cmnm}^{5} \mathrm{~s}^{2} \mathrm{U}$ wobble modification as $\mathrm{m}^{\mathrm{tRNA}}{ }^{\mathrm{Q}}$, was shown to be fully functional in mitochondrial protein synthesis (i.e., capable of decoding both AAA and AAG lysine codons), at least at normal temperature $\left(28^{\circ} \mathrm{C}\right)$ for growth on respiratory media (Kamenski et al. 2007). At higher growth temperatures $\left(37^{\circ} \mathrm{C}\right)$, the mitochondrial import of ${ }_{\mathrm{c}} \mathrm{tRNA}^{\mathrm{Lys}} \mathrm{CUU}$ (tRK1) becomes essential for the reading of AAG codons because the $\mathrm{cmnm}^{5} \mathrm{~s}^{2} \mathrm{U}$ wobble modification of $\mathrm{m}_{\mathrm{m}} \mathrm{RNA}{ }^{\text {Lys }}$ is impaired at $37^{\circ} \mathrm{C}$. However, this defect in $\mathrm{cmnm}^{5} \mathrm{~s}^{2} \mathrm{U}$ modification is specific for ${ }_{\mathrm{m}} \mathrm{tRNA}^{\mathrm{Lys}}$, since formation of $\mathrm{cmnm}^{5} \mathrm{~s}^{2} \mathrm{U}$ in ${ }_{\mathrm{m}} \mathrm{tRNA}{ }^{\mathrm{Q}}$ was not affected in the same conditions (Kamenski et al. 2007). We therefore believe that import of ${ }_{\mathrm{c}} \mathrm{tRNA}{ }^{\mathrm{Q}}$ for CAG codon translation purposes in mitochondria cannot be regarded as an absolute requirement. Furthermore, assuming that the two ${ }_{c} \mathrm{tRNAs}{ }^{\mathrm{Q}}$ would nevertheless be imported into yeast mitochondria, our data show that these species would be imported at a very low level, at least in the strains and growth conditions used in our work, which would question their involvement in mitochondrial translation.

Along the same lines, the report that ${ }_{c} \mathrm{QRS}$ is essential for mitochondrial protein synthesis is inconsistent with data obtained by us and others (Nabholz et al. 1997). If we assume that ${ }_{c} \mathrm{QRS}$ is responsible for $\mathrm{Q}-\mathrm{m}_{\mathrm{m}} \mathrm{RNA}^{\mathrm{Q}}$ synthesis, then blocking the mitochondrial import of ${ }_{c} E R S$ or deletion of any of the genes encoding GatFAB should not induce a respiratory-deficient phenotype (this work; Mulero et al. 1994; Kim et al. 1997). These considerations raise two possibilities: Either ${ }_{\mathrm{c}} \mathrm{QRS}$ is not imported into yeast mitochondria, or the fraction of ${ }_{c} Q R S$ that is imported does not participate to Q-m tRNA ${ }^{\mathrm{Q}}$ formation. To verify the latter, we engineered a ${ }_{c} Q R S$ variant fused to a canonical MTS and tried to complement an AdTdefective strain (Supplemental Table 1; Materials and Methods). Drop tests showed that this ${ }_{c}$ QRS variant is unable to complement the respiratory deficiency of a pet112 mutant, suggesting that even if ${ }_{c}$ QRS is addressed to mitochondria, it is unable to supply the mitochondrial translation apparatus with $\mathrm{Q}_{\mathrm{m}} \mathrm{tRNA}^{\mathrm{Q}}$ (Supplemental Fig. 3).

One of the most intriguing findings of our work is the fact that yeast ${ }_{c}$ ERS is preferentially localized in mitochondria in the absence of Arclp that acts as a cytosolic retention platform (Fig. 6). Dual localization of ${ }_{c}$ ERS is not the first example of a dual, cytosolic- and mitochondrial-localized protein in yeast and more generally in eukaryotes (Karniely and Pines 2005). Among proteins that are distributed between different subcellular compartments, four yeast aaRSs have already been shown to be dual-localized (Turner et al. 2000; Tang et al. 2004). However, in all cases studied so far, dual localization of a protein is almost always the result of translation of two different isoforms either from alternative splice variants or because translation begins at alternative start sites. Thus, both isoforms have different sequences, and since only one has a mitochondrial targeting signal, each isoform is restrained to a single cellular compartment. In the case of ${ }_{c} E R S$, both the cytosolic and the mitochondrial fractions have the same exact amino acid sequence. We could find only a few other examples whereby a single translation product is distributed between membrane-separated subcellular compartments. One is a $S$. cerevisiae adenylate kinase, Aky2, for which a portion of the enzyme is targeted to the intermembrane space of mitochondria while a fraction folds before the MTS accesses the mitochondrial import receptors and is therefore retained in the cytoplasm (Strobel et al. 2002). Another example is $S$. cerevisiae fumarase, for which all molecules are targeted to mitochondria and processed, but only a subset of the mature molecules is further translocated into the mitochondrial matrix while another 
fraction goes back to the cytoplasm by a retrograde movement (Stein et al. 1994; Knox et al. 1998). However, the strategy used to control dual, cytosolic and mitochondrial, localization of ${ }_{\mathrm{c}} \mathrm{ERS}$ is unprecedented and distinct from any example reported so far (Karniely and Pines 2005). The mechanism by which the ${ }_{c} E R S$ is retained in the cytoplasm is entrapment by binding to a cytosolic anchoring protein. We suspect that retention is very likely not achieved by masking of the ${ }_{\mathrm{c}}$ ERS MTS. The recent crystal structure of the binary complex made between the $\mathrm{N}$ termini of ${ }_{\mathrm{c}}$ ERS and Arclp favors our assumption, since it shows that only residues 122-131 and 157-173 of ${ }_{\mathrm{c}}$ ERS are involved in the interaction with Arclp (Simader et al. 2006). The entire Arclp-binding region has been deleted in the $\Delta \mathrm{N} 190{ }_{-\mathrm{c}} \mathrm{ERS}$ that is still imported and functional in mitochondria, as shown by unaffected growth on glycerol plates of the cers $\Delta 190$ strain (Fig. 4B). What was also unexpected is that although both subcellular fractions of the ${ }_{c}$ ERS have the same sequence, they catalyze two different reactions; in the cytosol, ${ }_{c}$ ERS produces E- ${ }_{c} \mathrm{tRNA}^{\mathrm{E}}$, while the mitochondrial subset forms $\mathrm{E}_{\mathrm{m}} \mathrm{tRNA}{ }^{\mathrm{Q}}$. We suspect that ${ }_{\mathrm{c}} \mathrm{ERS}$ has an intrinsic capacity to be nondiscriminating for the tRNA, but its association with Arclp in the cytosol restricts its specificity to only tRNA ${ }^{\mathrm{E}}$ charging, in agreement with the increased affinity of ${ }_{c}$ ERS for tRNA ${ }^{\mathrm{E}}$ mediated by binding to Arclp (Graindorge et al. 2005).

This study also shows that the role of Arclp is not confined to a catalytic enhancer, but that it constitutes a subcellular sorting platform whose expression is regulated in response to which metabolism-fermentation or respiration-is used by yeast. We showed that when yeast uses respiration, there is a decrease in the expression of Arclp that leads to release of ${ }_{c}$ ERS and enhanced import of this aaRS into the mitochondria in order to sustain increased levels of translation in this compartment. However, the molecular signaling pathway that controls the expression of Arclp in response to the switch from fermentation to respiration has yet to be deciphered. Since Arclp has also been shown to restrain ${ }_{c}$ MRS from going into the nucleus, our work suggests that under respiratory conditions there should also be an increase of nuclear targeting of ${ }_{c}$ MRS. The role of ${ }_{c} M R S$ inside the nucleus remains yet to be identified. Reports on highthroughput analyses of $S$. cerevisiae protein-protein interactions show that ${ }_{\mathrm{c}}$ MERS interacts with several nuclear proteins involved in gene transcription regulation and initiation (Gavin et al. 2002; Krogan et al. 2006). One of these interactants is Yll022c (HIF1), which is a component of the HAT-B histone acetyltransferase complex (Poveda et al. 2004), and another is Ygl112c (TAF6), a subunit of TFIID and SAGA complexes involved in transcription initiation by RNA polymerase II and in chromatin modification (Grant et al. 1998). One could easily speculate that ${ }_{\mathrm{c}}$ MRS could be involved in transcription regulation of certain genes, and since we suspect the nuclear localization of ${ }_{\mathrm{c}}$ MRS to be increased when there is a higher need for mitochondrial activity, one would speculate that the genes under the dependence of ${ }_{\mathrm{c}} \mathrm{MRS}$ could encode mitochondrial proteins.
Beyond subcellular localization of an aaRS, our data suggest that, in eukaryotes, proteins that have been identified so far to be cytosolic with certainty might nevertheless be capable of being addressed to mitochondria and display an essential function therein, even if a functional organellar ortholog of this cytosolic protein has already been identified. One can wonder whether Arclp could belong to a broader family of proteins that play the role of cytosolic anchors for proteins that so far have not been considered as being able to reach multiple subcellular destinations. In the light of our work, we suggest a re-examination of the pioneering studies on whole-cell protein-protein interaction networks that led to identification of many unsuspected multienzymatic complexes that are still waiting to be attributed a function. Perhaps gain of function is not the driving force that led to some of these protein-protein interactions, but rather dynamic control of subcellular distribution.

To conclude, our work describes three original aspects of organellar molecular biology. We prove that yeast Q- ${ }^{-}$tRNA $^{\mathrm{Q}}$ synthesis is formed by a bacterial-like AdT, displaying besides two canonical GatA and GatB subunits, a new type of fungi-specific subunit (GatF). We describe a new mechanism of dual-cytoplasmic and mitochondrial-localization of a protein whereby a preferentially mitochondrial protein is also maintained in the cytoplasm by binding to a cytosolic anchoring platform. And finally, we show that the dynamic sorting of this protein between the two compartments is mediated through regulation of the expression of the cytosolic anchoring protein upon the switch from fermentation to respiration.

\section{Materials and methods}

\section{Strains and oligonucleotides}

Yeast strains used and engineered for this study are described in Supplemental Table 1. Oligonucleotides and biotinylated oligonucleotides used as primers for PCR amplifications and as bait for tRNA affinity purification, respectively, are described in Supplemental Table 2.

\section{Engineering of PET112-TAP strain and TAP purification procedure}

The pet112-TAP strain was constructed as described previously (Puig et al. 2001), by homologous replacement of the chromosomal PET112 C terminus with the PCR product obtained by using oligonucleotides 1 and 2 and the pBS1479 plasmid for the amplification reaction. Twenty grams of cells of the pet112-TAP strain, obtained after $8 \mathrm{~h}$ of culture in YPD at $30^{\circ} \mathrm{C}$, were suspended in $20 \mathrm{~mL}$ of disruption buffer (Supplemental Material) and cells were disrupted using a cell disruptor working at $37 \mathrm{psi}$. The clear lysate obtained after $20 \mathrm{~min}$ of centrifugation at $12,000 \mathrm{~g}$, was subjected to the TAP procedure as described previously (Puig et al. 2001). The gel bands corresponding to each individual protein present in the final eluate were analyzed by mass spectrometry (MALDI-TOF).

Preparation of mitochondria, total mitochondrial tRNA, and mitochondrial protein extracts

Yeast mitochondria were isolated following the procedure described previously (Entelis et al. 2002; Boldogh and Pon 2007). 
Total mitochondrial tRNA was extracted from freshly purified mitochondria using the procedure described by Martin et al. $(1977,1979)$. Protein extracts of the mitochondrial matrix were prepared as follows: Fresh mitochondria, suspended in lysis buffer (Supplemental Material), were disrupted by sonication (VibraCell BioblockScientific) and centrifuged $20 \mathrm{~min}$ at $12,000 \mathrm{~g}$ to remove broken mitochondria and 90 min more at $105,000 \mathrm{~g}$ in order to pellet all cytosolic contaminants adsorbed on tiny membrane fragments. For Western blot purposes, the supernatant was directly transferred at $-80^{\circ} \mathrm{C}$. For aminoacylation and transamidation purposes, removal of contaminating mitochondrial tRNA from the supernatant was obtained by DEAE-cellulose chromatography (DE52, Whatman) following the manufacturer's instructions. Proteins eluting with $400 \mathrm{mM}$ $\mathrm{NaCl}$ were dialyzed against lysis buffer and used directly.

Cloning, overxpression, and purification of the yeast GatFAB $A d T,{ }_{m} E R S$, and ${ }_{c} E R S$

We designed the yeast gatFAB operon as described previously (Bailly et al. 2008) except that the 3 '-end of the gat $B$ gene was extended in-frame by the sequence encoding the V5 epitope and a $6 x$ His tag. The gatFAB operon was synthesized by Genscript with codon optimization, subcloned into pET20b (Novagen) between the NdeI and XhoI restriction sites, and the recombinant plasmid was transformed into E. coli BL21 $\lambda$ DE3 pLysS. Cytoplasmic ERS (GUS1) and mERS (MSE1) genes, deprived of their stop codons, were PCR-amplified from $S$. cerevisiae genomic DNA using oligonucleotide pairs 3, 4 and 5, 6 as primers, respectively. The PCR products were directly ligated into the $\mathrm{T} / \mathrm{A}$ expression vector $\mathrm{pBAD}-\mathrm{TOPO}$ (Invitrogen) that allows expression of the corresponding proteins C-terminally fused to the V5 epitope and to a 6xHis tag and were transformed into the E. coli Rosetta 2 strain. Expression and purification of soluble GatFAB AdT, ${ }_{m}$ ERS, and ${ }_{c}$ ERS were achieved as described in the Supplemental Material.

\section{Engineering of yeast expression plasmids of cERS and GatB} variants

Yeast strains cersfl, cers $\Delta 90$, cers $\Delta 190$, and cers $\Delta 199$ expressing wild-type ${ }_{\mathrm{c}} \mathrm{ERS}$ and the $\mathrm{N}$-terminally truncated variants $\Delta \mathrm{N} 90$ ${ }_{\mathrm{c}} \mathrm{ERS}, \Delta \mathrm{N} 190-_{\mathrm{c}} \mathrm{ERS}$, and $\Delta \mathrm{N} 199$ - $_{\mathrm{c}} \mathrm{ERS}$, respectively, were obtained by PCR amplification using $S$. cerevisiae genomic DNA as a template and the following primer pairs, respectively: oligonucleotides 7 and 8, oligonucleotides 9 and 8, and oligonucleotides 10 and 8 . The PCR products were digested with HindIII and BamHI and ligated into pRS315 digested with the same restriction enzymes. Genes of the truncated variants were cloned into pRS315 under the control of the NOP1 promoter. Transformation of the cersfl shuffle strain with the recombinant plasmids and plasmid shuffling experiments are described in the Supplemental Material. The gene encoding the first 199 amino acids of ${ }_{c}$ ERS fused to GFP ( $\mathrm{N}_{\mathrm{c}}$ ERS-GFP) was obtained, using $S$. cerevisiae genomic DNA as a template and oligonucleotide pair 11 and 12, by PCR amplification of a fragment of the cERS gene (GUS1) encompassing the 5' untranslated region (350 base pairs) and the first 603 nucleotides of the ORF flanked by the HindIII/BamHI restriction sites. The PCR product was ligated into pRS315-GFP. The resulting pRS315/N $\mathrm{N}_{\mathrm{c}}$ ERS-GFP plasmid was transformed into yeast BY4741 (ARC1, wild-type) or arc1 $\Delta$ strains. The yeast strain gatB-GFP, expressing GatB C-terminally fused to GFP (GatBGFP), was obtained using the same PCR and cloning strategy and oligonucleotide pair 13 and 14.

\section{Fluorescence and microscopy analysis}

Yeast strains gatA-GFP and gatF-GFP expressing the GatA and GatF subunits C-terminally fused to GFP, respectively, were grown in synthetic medium SCG until $\mathrm{A}_{600 \mathrm{~nm}}=0.3$, while the gatB-GFP strain was grown in SGC lacking leucine. A 1-mL aliquot of the cells was stained with $1 \mu \mathrm{L}$ of MitoTracker (Invitrogen) according to the manufacturer's instructions. After 20 min of incubation, cells were harvested by centrifugation, washed with fresh culture media, mounted on coverslips, and examined with a DIC Zeiss Axiovert 200M phase interference microscope using a $100 \times$ oil immersion objective (NO 1.4). Images were captured with a CoolSnap $\mathrm{HQ}^{2}$ camera and processed with Axiovision software. The same procedure was used for the visualization of the yeast $\operatorname{arc} 1 \Delta$ and BY4741 (ARC1) strains transformed with pRS315/Nter ${ }_{\mathrm{c}}$ ERS-GFP except that they were grown in synthetic medium SCG lacking leucine and visualized with a Zeiss LSM510 confocal microscope, using a $63 \times$ oil immersion objective (NO 1.4). Images were processed with the AIM3.2 software.

\section{Immunodetection analysis}

RS453 S100 extracts were used as controls to visualize the proportion of the cytosolic fraction of ${ }_{c}$ ERS. For all extracts, protein concentration was determined using Bradford, and 10-15 $\mu \mathrm{g}$ of proteins were separated by SDS-PAGE on a $12 \%$ gel prior to electroblotting to Hybond-P membrane (Amersham). Detection was carried out using HRP-conjugated goat anti-rabbit antibodies (Bio-Rad) and ECL reagents (Amersham) according to the manufacturer's instructions. We used anti-cERS primary antibody (1:5000) to quantify the amount of ${ }_{c} E R S$ in each extract. To control the relative quantity and purity of our mitochondrial protein preparations, we used as a mitochondrial matrix protein marker HSP70, which was detected using anti-HSP70 (1:1000), and as a cytosolic marker PGK, which was revealed using antiPGK (1:1000). For the quantification of Arclp and ${ }_{\mathrm{c}} \mathrm{MRS}$, we used anti-Arclp (1:5000), anti- ${ }_{\mathrm{c}}$ MRS (1:2000).

\section{Northern analyses of $t R N A$}

Detection of the ${ }_{\mathrm{m}} \mathrm{tRNA}^{\mathrm{Q}},{ }_{\mathrm{m}} \mathrm{tRNA}^{\mathrm{E}}, \mathrm{tRNA}^{\mathrm{K} 1}$, and ${ }_{\mathrm{c}} \mathrm{tRNA}^{\mathrm{Q}}$ was performed following a procedure previously described (Frugier et al. 2005) using $15 \mu \mathrm{g}$ of unfractionated yeast ${ }_{\mathrm{m}}$ tRNA prepared as described above or total yeast ${ }_{c}$ tRNA commercially available (Boehringer). We used $5 \mathrm{pmol}$ of the specific $\alpha\left[{ }^{32} \mathrm{P}\right]$-radiolabeled oligonucleotide probes 17, 18, 19, and 20, respectively (see Supplemental Table 2).

\section{tRNA purification}

Purification of ${ }_{\mathrm{m}} \mathrm{tRNA}^{\mathrm{Q}}$ and ${ }_{\mathrm{m}} \mathrm{tRNA}^{\mathrm{E}}$ from $1 \mathrm{mg}$ of unfractionated mitochondrial tRNA, prepared as described above, was performed using 5'-biotinylated specific oligonucleotides 15 and 16, respectively (see Supplemental Table 2), immobilized on streptavidine-agarose beads (Novagen) following the procedure described by Rinehart et al. (2005).

\section{Aminoacylation and transamidation assays}

The standard aminoacylation mixture $(100 \mu \mathrm{L})$ containing $100 \mathrm{mM}$ Na-Hepes (pH 7.2), $30 \mathrm{mM} \mathrm{KCl}, 10 \mathrm{mM}$ ATP, 12 $\mathrm{mM} \mathrm{MgCl} 2,30 \mu \mathrm{M} \mathrm{L}-\left[{ }^{14} \mathrm{C}\right]$ glutamate $\left(\left[{ }^{14} \mathrm{C}\right] \mathrm{E}\right)(330 \mathrm{cpm} / \mathrm{pmol}$, Amersham) or $1 \mu \mathrm{M} \mathrm{L}-\left[{ }^{3} \mathrm{H}\right]$ glutamate $\left(\left[{ }^{3} \mathrm{H}\right] \mathrm{E}\right)(3000 \mathrm{cpm} / \mathrm{pmol}$, Amersham), $0.1 \mathrm{mg} / \mathrm{mL}$ BSA, $0.15 \mu \mathrm{M}$ pure $\mathrm{m}_{\mathrm{tRNA}}{ }^{\mathrm{Q}}$ or pure ${ }_{\mathrm{m}}$ tRNA $^{\mathrm{E}}$ or $10 \mu \mathrm{M}$ total ${ }_{\mathrm{m}}$ tRNA, and $0.01 \mu \mathrm{M}_{\mathrm{m}}$ ERS or ${ }_{\mathrm{c}}$ ERS was 
incubated at $30^{\circ} \mathrm{C}$. For determination of the aminoacylation plateau, after incubation times ranging from 0 to $20 \mathrm{~min}, 10-\mu \mathrm{L}$ aliquots were withdrawn and TCA-precipitated, and the radiolabeled Glu-tRNA formed was determined by scintillation liquid counting. For transamidation purposes, the $\left[{ }^{14} \mathrm{C}\right] \mathrm{E}$ - or $-\left[{ }^{3} \mathrm{H}\right] \mathrm{E}-$ tRNA formed when plateaus were reached in a $40-$ to $50-\mu \mathrm{L}$ aminoacylation mixture was extracted using acid-buffered phenol and chloroform; the radiolabeled E-tRNA was precipitated with ethanol in the aqueous layer recovered by centrifugation, sedimented, and redissolved in water. The standard transamidation mixture $(50 \mu \mathrm{L})$ containing $100 \mathrm{mM}$ Na-Hepes, $30 \mathrm{mM} \mathrm{KCl}, 12 \mathrm{mM} \mathrm{MgCl}$, $10 \mathrm{mM}$ ATP, $1 \mathrm{mM}$ L-Gln (except for controls) as amide group donor, $0.03-0.1 \mu \mathrm{M}$ radiolabeled Glu-tRNA, and $100 \mathrm{nM} \mathrm{S}$. cerevisiae pure GatCAB AdT was incubated for $15 \mathrm{~min}$ at $30^{\circ} \mathrm{C}$. The $\left[{ }^{14} \mathrm{C}\right]$ - and $\left[{ }^{3} \mathrm{H}\right]$ aa-tRNA was ethanol-precipitated after phenol-chloroform extraction, dissolved in $50 \mu \mathrm{L}$ of water, and deacylated by $30 \mathrm{~min}$ of incubation at $80^{\circ} \mathrm{C}$ in the presence of $25 \mathrm{mM} \mathrm{KOH}$, followed by neutralization with $\mathrm{HCl}$. The hydrolysate was dried in a Speed-Vac, dissolved in $3 \mu \mathrm{L}$ of water, and fractionated by TLC on cellulose plates $(20 \times 20 \mathrm{~cm}$, Merck) extended by a $3 \mathrm{MM}$ Whatman paper sheet $(20 \times 5 \mathrm{~cm})$, with a solvent containing 2-propanol/formic acid/water $(80 / 4 / 20, v / v / v)$. The $\left[{ }^{14} \mathrm{C}\right]$ - and $\left[{ }^{3} \mathrm{H}\right]$-aa were revealed by scanning the 2-h-exposed image plate with a Fuji Bioimager.

\section{Acknowledgments}

We express our gratitude to Drs. I. Tarassov, N. Entelis, S. Friant, and J. Muterer for technical assistance and sharing of materials and equipment, and to Professor C. Stathopoulos and Dr. M. Blaise for critical reading. This work was supported by the University Louis Pasteur (Strasbourg), the Centre National de la Recherche Scientifique (CNRS), and the Association pour la Recherche sur le Cancer (ARC). M.F. was a recipient of a fellowship from the Ministère de $1^{\prime}$ Education Nationale de la Recherche et de la Technologie.

\section{References}

Bailly, M., Blaise, M., Lorber, B., Becker, H.D., and Kern, D. 2007. The transamidosome: A dynamic ribonucleoprotein particle dedicated to prokaryotic tRNA-dependent asparagine biosynthesis. Mol. Cell 28: 228-239.

Bailly, M., Blaise, M., Roy, H., Deniziak, M., Lorber, B., Birck, C., Becker, H.D., and Kern, D. 2008. tRNA-dependent asparagine formation in prokaryotes: Characterization, isolation and structural and functional analysis of a ribonucleoprotein particle generating Asn-tRNA(Asn). Methods 44: 146-163.

Becker, H.D. and Kern, D. 1998. Thermus thermophilus: A link in the evolution of the tRNA-dependent amino acid amidation pathway. Proc. Natl. Acad. Sci. 95: 12832-12837.

Boldogh, I.R. and Pon, L.A. 2007. Purification and subfractionation of mitochondria from the yeast Saccharomyces cerevisiae. Methods Cell Biol. 80: 45-64.

Bordonné, R. 2000. Functional characterization of nuclear localization signals in yeast Sm proteins. Mol. Cell. Biol. 20: 7943-7954.

Curnow, A.W., Hong, K., Yuan, R., Kim, S., Martins, O., Winckler, W., Henkin, T.M., and Söll, D. 1997. Glu-tRNA Gln amidotransferase: A novel heterotrimeric enzyme required for correct decoding of glutamine codons during translation. Proc. Natl. Acad. Sci. 94: 11819-11826.

Deinert, K., Fasiolo, F., Hurt, E.C., and Simos, G. 2001. Arclp organizes the yeast aminoacyl-tRNA synthetase complex and stabilizes its interaction with the cognate tRNAs. $J$. Biol. Chem. 276: 6000-6008.
Entelis, N.S., Kieffer, S., Kolesnikova, O.A., Martin, R.P., and Tarassov, I.A. 1998. Structural requirements of tRNALys for its import into yeast mitochondria. Proc. Nat1. Acad. Sci. 95: 2838-2843.

Entelis, N., Kolesnikova, O., Kazakova, H., Brandina, I., Kamenski, P., Martin, R.P., and Tarassov, I. 2002. Import of nuclear encoded RNAs into yeast and human mitochondria: Experimental approaches and possible biomedical applications. Genet. Eng. 24: 191-213.

Federovitch, C.M., Jones, Y.Z., Tong, A.H., Boone, C., Prinz, W.A., and Hampton, R.Y. 2008. Genetic and structural analysis of Hmg2p-induced endoplasmic reticulum remodeling in Saccharomyces cerevisiae. Mol. Biol. Cell 19: 45064520.

Frugier, M., Ryckelynck, M., and Giegé, R. 2005. tRNAbalanced expression of a eukaryal aminoacyl-tRNA synthetase by an mRNA-mediated pathway. EMBO Rep. 6: 860865.

Gagnon, Y., Lacoste, L., Champagne, N., and Lapointe, J. 1996. Widespread use of the glu-tRNA ${ }^{\text {Gln }}$ transamidation pathway among bacteria. A member of the $\alpha$ purple bacteria lacks glutaminyl-tRNA synthetase. J. Biol. Chem. 271: 1485614863.

Galani, K., Grosshans, H., Deinert, K., Hurt, E.C., and Simos, G. 2001. The intracellular location of two aminoacyl-tRNA synthetases depends on complex formation with Arclp. EMBO J. 20: 6889-6898.

Gavin, A.C., Bosche, M., Krause, R., Grandi, P., Marzioch, M., Bauer, A., Schultz, J., Rick, J.M., Michon, A.M., Cruciat, C.M., et al. 2002. Functional organization of the yeast proteome by systematic analysis of protein complexes. Nature 415: 141-147.

Golinelli-Cohen, M.P. and Mirande, M. 2007. Arc1p is required for cytoplasmic confinement of synthetases and tRNA. Mol. Cell. Biochem. 300: 47-59.

Graindorge, J.S., Senger, B., Tritch, D., Simos, G., and Fasiolo, F. 2005. Role of Arclp in the modulation of yeast glutamyltRNA synthetase activity. Biochemistry 44: 1344-1352.

Grant, P.A., Schieltz, D., Pray-Grant, M.G., Steger, D.J., Reese, J.C., Yates III, J.R., and Workman, J.L. 1998. A subset of TAF(II)s are integral components of the SAGA complex required for nucleosome acetylation and transcriptional stimulation. Cell 94: 45-53.

Huh, W.K., Falvo, J.V., Gerke, L.C., Carroll, A.S., Howson, R.W., Weissman, J.S., and O'Shea, E.K. 2003. Global analysis of protein localization in budding yeast. Nature 425: 686-691.

Ibba, M. and Söll, D. 2000. Aminoacyl-tRNA synthesis. Annu. Rev. Biochem. 69: 617-650.

Ibba, M., Becker, H.D., Stathopoulos, C., Tumbula, D.L., and Söll, D. 2000. The adaptor hypothesis revisited. Trends Biochem. Sci. 25: 311-316.

Kamenski, P., Kolesnikova, O., Jubenot, V., Entelis, N., Krasheninnikov, I.A., Martin, R.P., and Tarassov, I. 2007. Evidence for an adaptation mechanism of mitochondrial translation via tRNA import from the cytosol. Mol. Cell 26: 625-637.

Karniely, S. and Pines, O. 2005. Single translation-dual destination: Mechanisms of dual protein targeting in eukaryotes. EMBO Rep. 6: 420-425.

Kim, S.I., Stange-Thomann, N., Martins, O., Hong, K.W., Söll, D., and Fox, T.D. 1997. A nuclear genetic lesion affecting Saccharomyces cerevisiae mitochondrial translation is complemented by a homologous Bacillus gene. J. Bacteriol. 179: 5625-5627.

Knox, C., Sass, E., Neupert, W., and Pines, O. 1998. Import into mitochondria, folding and retrograde movement of fumarase in yeast. J. Biol. Chem. 273: 25587-25593. 
Krogan, N.J., Cagney, G., Yu, H., Zhong, G., Guo, X., Ignatchenko, A., Li, J., Pu, S., Datta, N., Tikuisis, A.P., et al. 2006. Global landscape of protein complexes in the yeast Saccharomyces cerevisiae. Nature 440: 637-643.

Kurata, S., Weixlbaumer, A., Ohtsuki, T., Shimazaki, T., Wada, T., Kirino, Y., Takai, K., Watanabe, K., Ramakrishnan, V. and Suzuki, T. 2008. Modified uridines with C5-methylene substituents at the first position of the tRNA anticodon stabilize U.G wobble pairing during decoding. I. Biol. Chem. 283: 18801-18811.

Lapointe, J., Duplain, L., and Proulx, M. 1986. A single glutamyltRNA synthetase aminoacylates tRNA Glu and tRNA ${ }^{\text {Gln }}$ in Bacillus subtilis and efficiently misacylates Escherichia coli tRNA $^{\text {Gln }}{ }_{1}$ in vitro. J. Bacteriol. 165: 88-93.

Martin, R.P., Schneller, J.M., Stahl, A.J., and Dirheimer, G. 1977. Study of yeast mitochondrial tRNAs by two-dimensional polyacrylamide gel electrophoresis: Characterization of isoaccepting species and search for imported cytoplasmic tRNAs. Nucleic Acids Res. 4: 3497-3510.

Martin, R.P., Schneller, J.M., Stahl, A.J., and Dirheimer, G. 1979. Import of nuclear deoxyribonucleic acid coded lysineaccepting transfer ribonucleic acid (anticodon C-U-U) into yeast mitochondria. Biochemistry 18: 4600-4605.

Mukherjee, S., Shukla, A., and Guptasarma, P. 2003. Singlestep purification of a protein-folding catalyst, the SlyD peptidyl prolyl isomerase (PPI), from cytoplasmic extracts of Escherichia coli. Biotechnol. Appl. Biochem. 37: 183-186.

Mulero, J.J., Rosenthal, J.K., and Fox, T.D. 1994. PET112, a Saccharomyces cerevisiae nuclear gene required to maintain rho+ mitochondrial DNA. Curr. Genet. 25: 299-304.

Nabholz, C.E., Hauser, R., and Schneider, A. 1997. Leishmania tarentolae contains distinct cytosolic and mitochondrial glutaminyl-tRNA synthetase activities. Proc. Natl. Acad. Sci. 94: 7903-7908.

Navarro, B., Rubino, L., and Russo, M. 2004. Expression of the cymbidium ringspot virus 33-kilodalton protein in Saccharomyces cerevisiae and molecular dissection of the peroxisomal targeting signal. J. Virol. 78: 4744-4752.

Poveda, A., Pamblanco, M., Tafrov, S., Tordera, V., Sternglanz, R., and Sendra, R. 2004. Hif1 is a component of yeast histone acetyltransferase B, a complex mainly localized in the nucleus. J. Biol. Chem. 279: 16033-16043.

Puig, O., Caspary, F., Rigaut, G., Rutz, B., Bouveret, E., BragadoNilsson, E., Wilm, M., and Seraphin, B. 2001. The tandem affinity purification (TAP) method: A general procedure of protein complex purification. Methods 24: 218-229.

Pujol, C., Bailly, M., Kern, D., Maréchal-Drouard, L., Becker, H., and Duchêne, A.M. 2008. Dual-targeted tRNA-dependent amidotransferase ensures both mitochondrial and chloroplastic Gln-tRNA ${ }^{\text {Gln }}$ synthesis in plants. Proc. Natl. Acad. Sci. 105: 6481-6485.

Reinders, J., Zahedi, R.P., Pfanner, N., Meisinger, C., and Sickmann, A. 2006. Toward the complete yeast mitochondrial proteome: Multidimensional separation techniques for mitochondrial proteomics. J. Proteome Res. 5: 1543-1554.

Rinehart, J., Horn, E.K., Wei, D., Söll, D., and Schneider, A. 2004. Non-canonical eukaryotic glutaminyl- and glutamyltRNA synthetases form mitochondrial aminoacyl-tRNA in Trypanosoma brucei. J. Biol. Chem. 279: 1161-1166.

Rinehart, J., Krett, B., Rubio, M.A., Alfonzo, J.D., and Söll, D. 2005. Saccharomyces cerevisiae imports the cytosolic pathway for Gln-tRNA synthesis into the mitochondrion. Genes \& Dev. 19: 583-592.

Rubio, M.A., Rinehart, J.J., Krett, B., Duvezin-Caubet, S., Reichert, A.S., Söll, D., and Alfonzo, J.D. 2008. Mammalian mitochondria have the innate ability to import tRNAs by a mechanism distinct from protein import. Proc. Natl. Acad. Sci. 105: 91869191.

Schön, A., Kannangara, C.G., Gough, S., and Söll, D. 1988. Protein biosynthesis in organelles requires misaminoacylation of tRNA. Nature 331: 187-190.

Sheppard, K., Yuan, J., Hohn, M.J., Jester, B., Devine, K.M., and Söll, D. 2008. From one amino acid to another: tRNAdependent amino acid biosynthesis. Nucleic Acids Res. 36: 1813-1825.

Simader, H., Hothorn, M., Köhler, C., Basquin, J., Simos, G., and Suck, D. 2006. Structural basis of yeast aminoacyl-tRNA synthetase complex formation revealed by crystal structures of two binary sub-complexes. Nucleic Acids Res. 34: 39683979.

Simos, G., Segref, A., Fasiolo, F., Hellmuth, K., Shevchenko, A., Mann, M., and Hurt, E.C. 1996. The yeast protein Arclp binds to tRNA and functions as a cofactor for the methionyland glutamyl-tRNA synthetases. EMBO J. 15: 5437-5448.

Stein, I., Peleg, Y., Even-Ram, S., and Pines, O. 1994. The single translation product of the FUM1 gene (fumarase) is processed in mitochondria before being distributed between the cytosol and mitochondria in Saccharomyces cerevisiae. Mol. Cell. Biol. 14: 4770-4778.

Strobel, G., Zollner, A., Angermayr, M., and Bandlow, W. 2002. Competition of spontaneous protein folding and mitochondrial import causes dual subcellular location of major adenylate kinase. Mol. Biol. Cell 13: 1439-1448.

Tang, H.L., Yeh, L.S., Chen, N.K., Ripmaster, T., Schimmel, P., and Wang, C.C. 2004. Translation of a yeast mitochondrial tRNA synthetase initiated at redundant non-AUG codons. $J$. Biol. Chem. 279: 49656-49663.

Tumbula, D.L., Becker, H.D., Chang, W.-Z., and Söll, D. 2000. Domain-specific recruitment of amide amino acids for protein synthesis. Nature 407: 106-110.

Turner, R.J., Lovato, M., and Schimmel, P. 2000. One of two genes encoding glycyl-tRNA synthetase in Saccharomyces cerevisiae provides mitochondrial and cytoplasmic functions. J. Biol. Chem. 275: 27681-27688.

Tzagoloff, A. and Shtanko, A. 1995. Mitochondrial and cytoplasmic isoleucyl-, glutamyl- and arginyl-tRNA synthetases of yeast are encoded by separate genes. Eur. J. Biochem. 230: 582-586.

Umeda, N., Suzuki, T., Yukawa, M., Ohya, Y., Shindo, H., Watanabe, K., and Suzuki, T. 2005. Mitochondria-specific RNA-modifying enzymes responsible for the biosynthesis of the wobble base in mitochondrial tRNAs. Implications for the molecular pathogenesis of human mitochondrial diseases. J. Biol. Chem. 280: 1613-1624.

Yokoyama, S. and Nishimura, S. 1995. Modified nucleosides and codon recognition. In tRNA: Structure, biosynthesis and function (eds. U. RajBhandary and D.Söll), pp. 207-233. American Society for Microbiology Press, Washington, DC. 


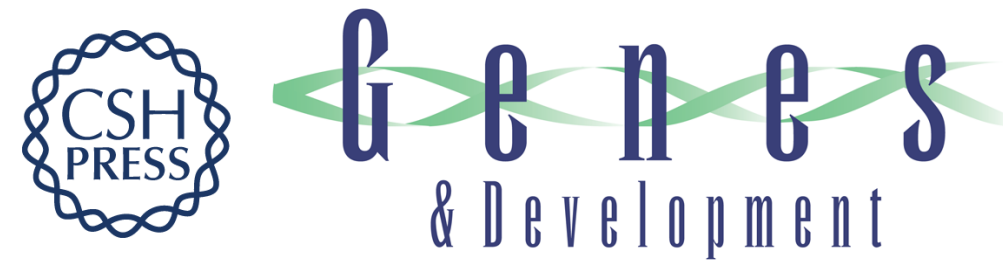

\section{Yeast mitochondrial GIn-tRNA GIn is generated by a GatFAB-mediated transamidation pathway involving Arc1p-controlled subcellular sorting of cytosolic GluRS}

Mathieu Frechin, Bruno Senger, Mélanie Brayé, et al.

Genes Dev. 2009, 23:

Access the most recent version at doi:10.1101/gad.518109

Supplemental http://genesdev.cshlp.org/content/suppl/2009/05/08/23.9.1119.DC1

Material

References This article cites 51 articles, 25 of which can be accessed free at: http://genesdev.cshlp.org/content/23/9/1119.full.html\#ref-list-1

License

Email Alerting Receive free email alerts when new articles cite this article - sign up in the box at the top Service right corner of the article or click here.

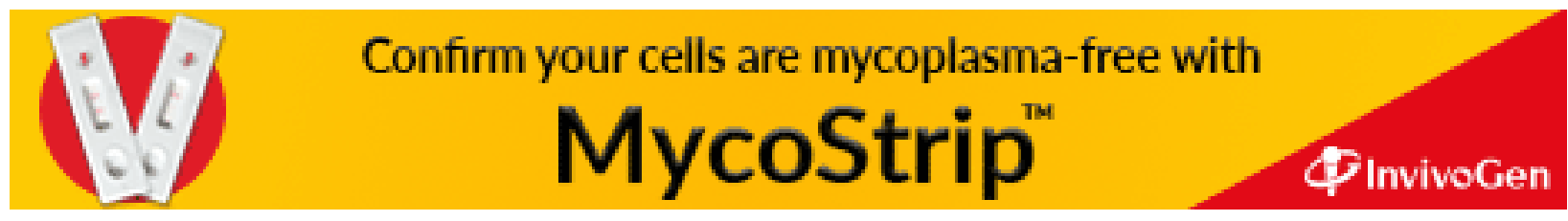

